\title{
Del lienzo a la pantalla digital. La experiencia del museo en la era de la intermediación electrónica
}

\section{From canvas to digital screen. The museum's experience in the age of electronic intermediation}

Carolina da Rocha C. Matos ${ }^{\mathrm{a}}$

a Universidad Complutense de Madrid, carolinadarocha@ucm.es

\begin{abstract}
Resumen
Hasta finales del siglo XX, las tecnologías de la memoria se limitaban a la utilización de medios analógicos como soporte para la preservación y transmisión del pasado. Con la creciente presencia del formato digital en el ámbito cultural, la gestión de la memoria pasa a contar también con la gestión de archivos numéricos y bases de datos. En los museos y centros culturales de la actualidad, el rápido desarrollo de tecnologías destinadas a la digitalización de colecciones e intermediación de la experiencia del espectador contemporáneo en contacto con el patrimonio histórico y cultural provoca una reconfiguración contundente tanto en las prácticas laborales como los modelos expositivos actuales. Entre varios tipos de aparatos tecnológicos digitales para la comunicación e interacción, la pantalla táctil de los teléfonos móviles reclama la atención y demanda la participación del observador contemporáneo, a la vez que genera posibilidades de contemplación y reflexión sobre el contenido presentado que trascienden la materialidad del objeto.
\end{abstract}

Palabras clave: historia del arte; filosofia de la cultura; museos; patrimonio cultural; pantalla digital.

\footnotetext{
Abstract

Until the end of the last century, memory technologies were limited to the use of analog format as a medium for the preservation and transmission of the past. With the growing presence of digital media in the cultural sphere, memory management comes to rely on the treatment of numerical files and databases. In today's museums and cultural centers, the rapid development of technologies aimed at digitizing collections and mediating the contemporary viewer's experience in contact with historical and cultural heritage causes a resounding reconfiguration, both in current work practices and exhibition
} 
Del lienzo a la pantalla digital. La experiencia del museo en la era de la intermediación electrónica.

models. Among various types of digital devices for communication and interaction with the pucblic, the touch screen of mobile phones calls for the attention and demands the participation of the contemporary observer, at the same time it generates possibilities for contemplation and reflection on the content that transcend the materiality of the object.

Keywords: history of art; philosophy of culture; museums; cultural heritage; digital screen. 


\section{Introducción}

De la misma manera que la electricidad desencadenó la revolución industrial en el siglo XIX, la electrónica generó el contexto de la revolución digital en la que vivimos hoy. La cultura y el patrimonio histórico no pueden dejar de ser observados bajo este recorte temático, siendo la era de la información el escenario donde se desarrolla actualmente la relación entre los museos y las instituciones culturales y sus públicos. Los objetos protegidos por el ámbito de los museos, ya sean obras de arte o piezas históricas, pueden sufrir cambios conceptuales a partir de las innovaciones presentes en los procesos de mediación digital. Las experiencias digitales en el ámbito de la cultura son actualmente piezas fundamentales para la creación de encuentros que repercuten a través de la interactividad en la propia constitución de la identidad cultural.

Como en el Renacimiento, con el advenimiento de la perspectiva, o en el siglo XIX, con el surgimiento de la fotografía, vivimos con la digitalización masiva de la comunicación una transición sin retorno, tanto en lo que concierne a la producción como en la difusión de imágenes. Como consecuencia directa, nace también un nuevo tipo de observador y visitante de los museos.

Actualmente, dos tercios de la población mundial tiene acceso a un teléfono móvil con conexión a Internet 1. Este trabajo tiene el objetivo de reflexionar sobre cómo las instituciones de arte relacionarse pueden con el público a través de los principales medios de comunicación que se utilizan en la actualidad. Es fundamental que las organizaciones culturales, que están al servicio de la sociedad y su desarrollo y que desean democratizar la información que poseen, consideren la pantalla digital como un agente de conexión, como un intermediario entre el visitante y sus colecciones.

Casi todos los años aparecen nuevos modelos de equipos con pantallas interactivas, así como nuevas prácticas y tendencias en la cultura visual. Por otro lado, la obsolescencia tecnológica nos obliga a repensar el uso de los medios digitales a medida que se desarrollan. Todavía muy reciente, este cambio de paradigma tan abrumador entre el régimen visual analógico y digital nos sitúa en medio de un punto de inflexion importante para la historia de los museos.

Somos la última generación bilingüe, analógico-digital, que puede reflexionar en primera persona sobre las limitaciones y diferencias de la cultura visual pre-digital. Los nativos digitales, como se llama a los sujetos nacidos bajo la ubicuidad dominante de las pantallas clickables, no visitarán los museos con la misma sensación que los niños de la radio y la televisión sin demanda. La percepción visual del siglo XXI se gestiona desde otro repertorio de imágenes, e incluso formatos, y por tanto es fruto de otra cultura visual.

La visita al museo ya no es meramente contemplativa, y la experiencia se convierte en la palabra clave de un nuevo modelo expositivo, capaz de abarcar toda una cadena de

1 GSM Association (2020). THE MOBILE ECONOMY 2020. < content/uploads/2020/03/GSMA_MobileEconomy2020_Global.pdf > [Consulta: 13/02/2021] 
significados más allá de la pura observación pasiva. Por tanto, el concepto de visita como experiencia se convierte en el epicentro de la relación de un museo contemporáneo con su público. En este contexto, la interactividad es fundamental, siendo una de las posibilidades de diálogo que cobró más fuerza con la adopción de la tecnología digital.

En el campo de la práctica, la pantalla digital ha ganado una importancia irrefutable dentro del trabajo en el campo museológico, equivalente a la que ha ido adquiriendo en el día a día de nuestras vidas. Desde la última década, hemos observado que la estructura organizativa de los recursos humanos y tecnológicos en las instituciones culturales, como galerías, bibliotecas, archivos y museos, sufre constantes renovaciones.

Podemos ver gradualmente cómo la representación supera el tabú que la asocia con la pérdida del aura de la obra de arte, donde el creciente interés por el conocimiento y acercamiento al arte en el ciberespacio ayuda a construir una nueva reputación para la representación digital. Aludiendo al concepto de aura de la información (Betancourt, apud Perssinoto y Barreto, 2010) podemos decir que en el siglo XXI, cuanto más vista la imagen de una obra, mayor relevancia adquiere en el panorama cultural mundial.

Esta comunicación explora especialmente algunos conceptos clave para la realidad de la transformación digital en museos e instituciones culturales, como la noción de museo intangible y el diseño de la experiencia del usuario, prácticas pertenecientes a un espacio virtual y realizadas a través del uso de dispositivos digitales. Para mapear las principales tendencias tecnológicas en museus en la última década, se toma como base el NMC Horizon Report: Museum Edition2, que a través de la evolución observada entre todas sus ediciones, presenta el escenario de algunos desafíos que enfrentan las instituciones culturales en la adopción de esta nueva dinámica relacional con sus públicos.

Este artículo refleja parcialmente los resultados de la tesis doctoral en Historia del Arte en la Universidad Complutense de Madrid, titulada "Del lienzo a la pantalla digital. La experiencia del museo en la era de la intermediación electrónica", presentada en 2020 y dirigida por las Doctoras María Concepción Casajús Quirós (UCM) y Cecilia Carrossini Bezerra Cavalcanti (UFRJ).

\section{Los museos virtuales y la experiencia del espectador}

La idea de que la creación de museos impuso a la sociedad una relación totalmente nueva con la obra de arte es una tesis del exministro de Cultura francés André Malraux y aparece en la primera página de su ensayo titulado "El museo imaginario" (Malraux, 2013). En esta obra, el escritor habla de la idea de un museo sin paredes, en el que cada persona puede crear su propia colección.

Para lograr este arquetipo, Malraux apunta la función de la reproducción fotográfica como instrumento de la documentación cultural, que acerca las obras de arte a individuos distantes

2 https://library.educause.edu/resources/2016/1/horizon-report-museum-edition-2010-2016\%20 [Consulta: 01/02/2021]. 
a través de la imagen, en un nuevo formato portátil que trasciende el tiempo y la distancia. El museo imaginario consta de una colección de imágenes, reproducciones bidimensionales de obras de arte originales. En elogio de la técnica fotográfica, que generó nuevas formas de ver a partir del siglo XIX, este museo dependería más de la visión que incluso de la imaginación o la memoria.

"La memoria óptica no es infalible, y varias semanas separaban, a menudo, el examen de dos telas. Desde el siglo XVII hasta el XIX, los cuadros, traducidos por el grabado, se habían convertido en grabados: habían conservado el dibujo, perdido el color, al que había sustituido, no por copia, sino por interpretación, su expresión en blanco y negro; habían perdido también las dimensiones y adquirido márgenes. La fotografía en negro del siglo XIX no fue sino un grabado más fiel. El aficionado de entonces conoció las telas como nosotros conocemos los mosaicos y los vitrales...

Hoy un estudiante dispone de la reproducción en colores de la mayor parte de las obras maestras, descubre una cantidad de pinturas secundarias, las artes arcaicas, las esculturas india, china y precolombina de las primeras épocas, una parte del arte bizantino, los frescos románicos y ciertas artes primitivas y populares.” (Malraux, 2013).

Otro proyecto de museo de imágenes, incluso anterior a la idea de Malraux, fue el "Atlas Mnemosyne" (Warburg, 2010), obra inacabada del historiador de arte alemán Aby Warburg, realizada en la década de 1920. Su idea fue la de un modelo expositivo con un enfoque de espacio visual dinámico, abierto e infinito. Aunque incompleto, consistió en una recopilación de dos mil imágenes articuladas en sesenta tablas, compuestas por fotografías de obras de arte, fragmentos de prensa, entre otros tipos de imágenes documentales. Cada grupo fue diseñado según sus analogías y acompañado de un epígrafe textual que sirvió de guía para la interpretación de las imágenes. La idea de Warburg era hacer correspondencias entre símbolos e imágenes que se cruzan en el espacio y el tiempo, arquetipos que han migrado desde la antigüedad, en una "experiencia de pensamiento figurativo-espacial, que es el resultado del contacto real con los objetos" (Reguera, 2010).

Adotparemos el término "intangible" para referirnos a una realidad cuya naturaleza nos impide sentir físicamente. "Resulta, por tanto, primordial no confundir intangible con digital, ni incluso con virtual” (Rico 2009, p. 101). Para el teórico francés Philippe Quéau, "lo $<<$ virtual $>>$ nos propone otra experiencia de lo $<<$ real $>>$. [...] Las experiencias virtuales son a priori asimilables a las experiencias sensoriales $<<$ reales $>>$ que vamos acumulando $<<$ naturalmente $>>$ " (Quéau, 1995, p. 17).

¿Qué pensarían Aby Warburg y André Malraux si pudieran hacer una búsqueda en GOOGLE y, más concretamente, acceder a la amplia oferta de repositorios de imágenes digitales de museos de todo el mundo? ¿Serían capaces de elaborar algunos de los recursos digitales que, en el siglo XXI, hacen virtualmente todo lo que evocan sus textos de mediados del siglo XX?

Al partir del concepto de museo virtual e intangible en el "Museo Imaginário" y el "Atlas Mnemosyne", se puede pensar la comprensión del núcleo del museo digital actualmente, 
donde la imagen digital actúa en la preservación del patrimonio como los semióforos, signos de una época remota que el escritor italiano Umberto Eco menciona en referencia al historiador polaco Krzysztof Pomian (Eco, 2014). Es el carácter intangible de la memoria que transporta el tiempo del pasado al presente, mostrando el valor de culto de la obra y su importancia simbólica para la sociedad a través de la imagen.

El salto temporal y conceptual entre el pensamiento de Warburg y Malraux, de que muy pocas personas tendrían la suerte de poder visitar todos los museos que quieran o ver todas las obras de arte que les interesan en el mundo, para el surgimiento de la tecnología digital, el Internet y las pantallas táctiles, evidencia la revolución visual y relacional que la innovación tecnológica ha generado en el campo cultural. Sería realmente impensable reunir todo el volumen de objetos e información de este campo en un solo lugar de forma analógica.

En este sentido, podemos mencionar la iniciativa GOOGLE ARTS \& CULTURE, como un proyecto pionero más popularizado en la última década, inaugurando un ambiente de aproximación con el publico en la práctica cultural en entornos virtuales. Actualmente, la plataforma cuenta con la adhesion de más de doscientas instituciones de arte en más de cuarenta países. Al utilizar la tecnologia del GOOGLE STREET VIEW para ofrecer una calidad de navegación que acerca al espectador a la noción del espacio físico de las galerías, la iniciativa de GOOGLE sirve como una parodia de transición entre la experiencia de la visita presencial y la visita virtual.

Pero GOOGLE cumple con su función central de agregar contenido y no pretende desempeñar ningún papel curatorial, siendo la elección del concepto central que transmite el encuentro con la información contenida en una obra de arte responsabilidad de los museos, que eligen que contenido quieren incluir en el programa, en base a motivos específicos y particulares. Como en un museo, el "paseo" virtual que lleva un sujeto hasta una obra por los pasillos del edifício, el recurrido de la visita virtual debe ser el camino que lleva al encuentro con la obra.

Históricamente, las obras siempre han estado ancladas al lugar hasta que se produjo el fenómeno de la reproducción. Hasta hace apenas algunos siglos, la mayoría de las personas tenía acceso al arte exclusivamente en las Iglesias y solo los más ricos tenían el privilegio de ostentar imágenes en el ámbito residencial (Jiménez-Blanco, 2014). Hoy en día, las imágenes están en todas partes, incluso superando al texto como forma de comunicación dominante.

En la misma dirección que GOOGLE, muchos museos han comenzado a emprender la digitalización de sus colecciones como medida para conferir acceso amplio y democrático a sus colecciones en el última década. El Rijksmuseum de Amsterdam fue uno de los pioneros en esta práctica, aprovechando el cierre de sus instalaciones físicas para una renovación como pretexto para reformular también su política de acceso a través de la extensa digitalización de su colección. Actualmente, el museo fomenta la interacción digital como política de difusión con el lema "desde casa te traemos el museo", y pone a disposición, de forma 
totalmente libre de derechos de uso, más de setecientas mil imágenes digitales de sus obras en su herramienta online Rijkstudio3.

Otro proyecto que traduce parcialmente la idea de un panel de imágenes que condensa tiempos, espacios y conceptos culturales y sociales en un mismo lugar es THE MUSEUM OF THE WORLD4, línea del tiempo del British Museum en alianza con GOOGLE. Es una experiencia para navegadores de Internet, por lo tanto, pensada para el espacio virtual y que genera conexiones que solo serían posibles de esta manera. El poder que genera la unión de lugares lejanos y tiempos separados con imágenes, combinado con información de audio, mapas y textos, ofrece la posibilidad de una conexión con el contenido que no depende de la materialidad.

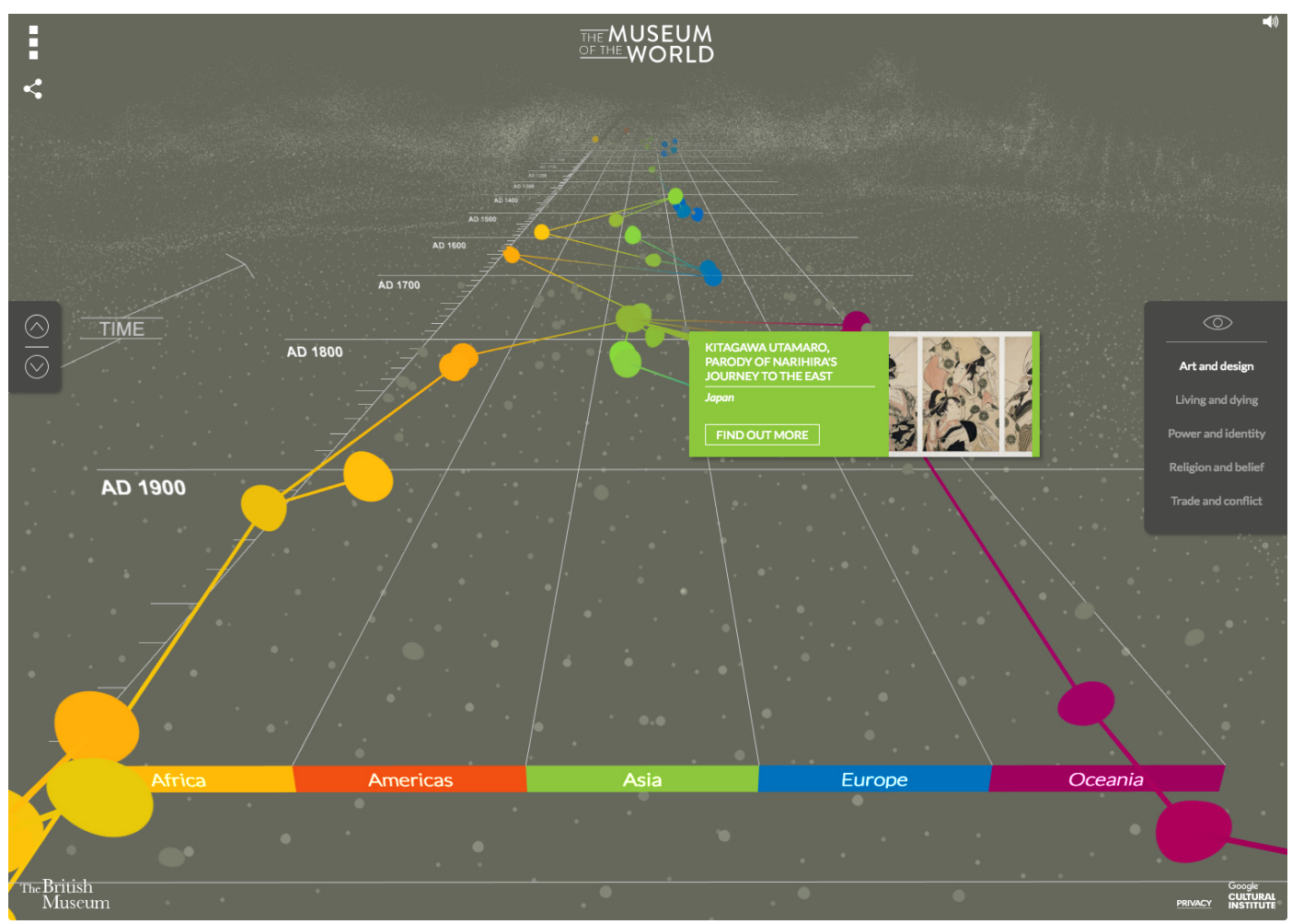

Fig. 1 Catpura de pantalla de la navegación en la página del proyecto "The Museum of the World", realizado por el British Museum con GOOGLE.

A través de esta nueva forma de visualización de imagines de obras de arte, volvemos a los conceptos explorados por el "Atlas" o el "Museo Imaginario", donde el visitante virtual puede

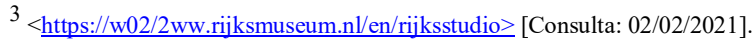

$4<$ https://britishmuseum.withgoogle.com/> [Consulta: 02/02/2021]
} 
disfrutar de experiencias visuales diseñadas exclusivamente para la plataforma digital y situadas en la pantalla. La experiencia del espectador se amplifica por la posibilidad de construir empatía a partir de la visualización de significados vinculados a un objeto histórico y artístico, reposicionando la dinámica del encuentro cara a cara de una manera que ya no puede ser ignorada por los museos y instituciones culturales en el mundo nuevo milenio.

\section{El diseño de la visita como experiencia.}

En el contexto actual, el diseño de la experiencia de usuario, o el UX Design, es una práctica que puede conectar de manera efectiva y objetiva a los usuarios de los servicios digitales con los agentes de la cultura. Se trata de un enfoque dinámico del Diseño, en el que prevalece la comprensión de las necesidades de los usuarios para la creación de productos y servicios digitales que sean fáciles de usar para las personas. El enfoque de la producción de la experiencia, en este caso, debe ser la perspectiva del usuario final, no de quién la está desarrollando.

A través de encuestas com los visitantes y análisis de los datos de acceso, las instituciones culturales buscan conocer al visitante que accede a su contenido digital, sus motivaciones para la visita virtual, sus necesidades y expectativas al navegar por la colección online (Villaespesa, 2015). Al recopilar la información necesaria para el diseño de una aplicación, los profesionales del museo pueden anteponer las necesidades de los visitantes a las necesidades específicas del proyecto o institución. El diseño de interfaces digitales debe priorizar la calidad de la interacción con el público para crear formas visuales de satisfacer sus expectativas.

De esta forma, pueden establecer una conexión empática con las personas, buscando una comprensión real de los sentimientos y emociones presentes para los visitantes cuando entran en contacto con la colección. Un diseño exitoso se traduce en un mayor acceso y una mayor interacción y lealtad, valores que los museos y las instituciones culturales deben apreciar en tiempos de confinamiento y estimulación visual y sensible exacerbada.

Podemos decir que el principal cambio de percepción en el universo cultural con la introducción de herramientas digitales como el UX Design es el incentivo para construir un diálogo democrático, en el que los destinatarios del mensaje participan en su construcción y comparten, de cierta manera, la dinámica con los titulares del discurso. A través de la nueva lógica del ciberespacio, el individuo contemporáneo puede compartir la elaboración del mensaje que recibe. Por lo tanto, el tipo de interactividad creado con la comunicación digital se adapta a la velocidad y la naturaleza global del intercambio de información actual. La digitalización provoca la creación de mensajes que no solo son móviles, sino infinitamente modificables.

Due to the fluid or variable nature of digital media, many digital art works are reconfigured each time they are exhibited. Even more to the point, many digital art works are reconfigured each time they are experienced and re-configured differently for each person experiencing 
them. They may be experienced differently when delivered across the Internet and presented on a vast range of home computers with custom combinations of network speeds, monitor sizes and settings, and media card capabilities. They may be instantly reconfigured because they are the result of user-input interacting with live computational processes that never produce the exact same results twice. [...] Of course artworks in any medium change over time due to things like lighting or chemical decay, but digital media art changes more often, at a faster pace, purposefully, and in ways so immediately observable that they have direct implications for intellectual property.5 (Rinehart, 2006).

En los últimos veinte años han aparecido en el escenario mundial multitud de nuevas tecnologías digitales, pero la velocidad con la que se adoptan y normalizan en la vida cotidiana del sujeto contemporáneo hace que pierdan el título de "nuevas" con la misma celeridad que aparecen y se vuelven habituales. Antes de diseñar lo que será la experiência del museo a través de la intermediación electrónica de la pantalla digital, es necesario comprender mejor el impacto del uso de lo que llamamos Tecnologías de la Información y la Comunicación (TIC) en los museos.

El análisis de las seis ediciones del NMC Horizon Report - Museum Edition, publicadas entre 2010 y 2016, sirven como base para mapear las tendencias tecnológicas en en este ámbito. Son relatórios producidos con la colaboración de un cuerpo internacional de profesionales de instituciones culturales de todo el mundo, incluidos especialistas en museos, educación, tecnología y otros campos, que presentan una selección de avances tecnológicos que aceleran la adopción de la tecnología digital en museos y analisan su impacto y uso para la educación e interpretación en este entorno.

Como ya mencionado, las aplicaciones para teléfonos móviles son una realidad cada vez más presente en el día a día de los visitantes de museos y centros culturales. A partir de 2013, la tendencia principal en el horizonte de adopción de tecnologías descritas en la Tabla 1 evoluciona naturalmente a una práctica conocida como BYOD (bring your own device o traiga su propio dispositivo). La utilización de estos aparatos permite el empleo de otras prácticas mencionadas en el gráfico, sirviendo de soporte para el disfrute de los recursos digitales in loquo o de manera remota.

5 http://www.coyoteyip.com/rinehart/papers files/Nailing_down bits.pdf [Consulta: 20/09/2020] Traducción de la autora: "Debido a la naturaleza fluida o variable de los medios digitales, muchas obras de arte digital se reconfiguran cada vez que se exhiben. Más concretamente, muchas obras de arte digital se reconfiguran cada vez que se experimentan y se reconfiguran de manera diferente para cada persona que las experimenta. Se pueden experimentar de manera diferente cuando se envían a través de Internet y se presentan en una amplia gama de computadoras domésticas con combinaciones personalizadas de velocidades de red, tamaños y configuraciones de monitores y capacidades de tarjetas de medios. Pueden reconfigurarse instantáneamente porque son el resultado de la interacción del usuario con procesos computacionales en vivo que nunca producen exactamente los mismos resultados dos veces. [...] Por supuesto que las obras de arte en cualquier medio cambian con el tiempo debido a factores como la iluminación o la descomposición química, pero el arte de los medios digitales cambia con más frecuencia, a un ritmo más rápido, con un propósito y de maneras tan inmediatamente observables que tienen implicaciones directas para la propiedad intelectual." 
Un aparato de uso personal ofrece a los museos la oportunidad de establecer conexiones individuales con los visitantes a la vez que permite también la comunicación con audiencias que tradicionalmente están subrepresentadas, basándose en la interacción individual y dirigida. Del punto de vista de la producción, que la experiencia sea acedida a través de la conexión con los teléfonos móviles hace con que las instituciones puedan reducir los costos generales de servicios como la compra de entradas y los audioguías, por ejemplo. Por lo tanto, los fondos asignados al presupuesto de compra de equipos se pueden redistribuir en otras partes del museo, como la producción de contenido digital.

Tabla 1. Tecnologías emergentes en los museos entre 2010-2016, según el NMC Horizon Report: Museum Edition

\begin{tabular}{|c|c|c|c|}
\hline $\begin{array}{l}\text { Horizonte de } \\
\text { adopción } \\
\text { Año del } \\
\text { informe }\end{array}$ & hasta 12 meses & de 2 a 3 años & de 4 a 5 años \\
\hline & Aplicaciones para teléfonos móviles & Realidad aumentada & Computación basada en gestos \\
\hline 2010 & Redes sociales & Servicio basado en la localización & Web semántica \\
\hline 2011 & Aplicaciones para teléfonos móviles & Realidad Aumentada & Preservación digital \\
\hline & Tablets & Publicación electrónica & Objetos inteligentes \\
\hline & Aplicaciones para teléfonos móviles & Realidad aumentada & Internet de las cosas \\
\hline 2012 & Redes sociales & $\begin{array}{l}\text { Contenido abierto } \\
\text { (OC - OpenContent) }\end{array}$ & $\begin{array}{l}\text { Interfaz natural de usuario } \\
\text { (NUI - Natural User Interfaces) }\end{array}$ \\
\hline & $\begin{array}{l}\text { Traiga su propio dispositivo } \\
\text { (BYOD - Bring your own device) }\end{array}$ & Publicación electrónica & $\begin{array}{l}\text { Interfaz natural de usuario } \\
\text { (NUI - Natural User Interfaces) }\end{array}$ \\
\hline 2013 & $\begin{array}{l}\text { Crowdsourcing } \\
\text { (Colaboración abierta distribuida) }\end{array}$ & Servicio basado en la localización & Tecnologías de preservación y conservación \\
\hline & $\begin{array}{l}\text { Traiga su propio dispositivo } \\
\text { (BYOD - Bring your own device) }\end{array}$ & Servicio basado en la localización & $\begin{array}{l}\text { Interfaz natural de usuario } \\
\text { (NUI - Natural User Interfaces) }\end{array}$ \\
\hline 2015 & Juegos y Gamificación & Espacios maker & El Internet de las cosas \\
\hline 2016 & $\begin{array}{l}\text { Tecnologías de humanidades digitales } \\
\text { Espacios maker }\end{array}$ & $\begin{array}{l}\text { Inteligencia de localización } \\
\text { (LI - Location intelligence) } \\
\text { Realidad virtual }\end{array}$ & $\begin{array}{l}\text { Information visualization } \\
\text { Objetos en red } \\
\text { (networked objects) }\end{array}$ \\
\hline
\end{tabular}

Aunque en la última década se han creado varias redes de conexiones digitales entre los museos y su público, un movimiento engendrado por avances tecnológicos como los ejemplificados en la tabla anterior, existen muchos obstáculos en el camino de la transformación digital que tienen que ser superarados en con el fin de generar experiencias digitales significativas en el ámbito de la cultura. La última década también estuvo marcada por la experimentación en medio de una dinámica aún embrionaria en los museos, y muchas de las conclusiones para la elaboración del mencionado Horizon Report también se basaron en errores y correcciones de ruta.

Si bien existen factores locales que pueden afectar la adopción y el uso de estas tecnologías, también existen problemas que trascienden las fronteras regionales y son comunes a todos. Aunque no refleja la realidad del Sur global, por ejemplo, las tendencias enumeradas en el texto reflejan las más significativas entre las instituciones pioneras en el proceso de 
transformación digital en el período analizado por el Horizon Report, divididas en un panorama temporal de adopción entre corto, mediano y largo plazo.

La realidad en el proceso de digitalización de las prácticas museológicas implica un cambio notable en la rutina de los agentes de esta rápida e impactante transición, siendo los profesionales de los museos y las instituciones culturales los primeros en tener que adaptar sus conocimientos para traducir la experiencia de la visita, sea física o virtual, para el lenguaje de visitantes hiperconectados y ávidos por consumir contenidos de forma interactiva y simplificada. Las pantallas táctiles digitales comienzan a reemplazar las vitrinas y permiten al espectador interactuar, navegar, viajar y elegir sus caminos entre obras, colecciones y archivos.

Como base para el éxito en la comunicación digital, las especificidades del propio medio digital deben ser respetadas para que el contacto con el contenido tenga sentido en este modelo de interacción, no bastando con adaptar lo que sería la visualidad de la visita en el museo a un conjunto de imágenes puestas a disposición online para su consulta. Es necesario ir más allá y cuando se habla de diseñar la experiencia del museo y diseñar la experiencia del usuario, las instituciones culturales deben pensar en el visitante para el que la experiencia está diseñada, el observador, el espectador o el consumidor de arte al que se destina. Al igual que en el museo, el visitante virtual necesita recorrer un camino para llegar a la información y si esa experiencia es lo suficientemente impactante como para facilitar la rentención de la información o la sensación como memoria activa, el encuentro también puede contribuir al aprendizaje.

\section{Conclusiones}

El proceso de transformación digital en las instituciones culturales, práctica reconocida por el Consejo Internacional de Museos (ICOM) en la celebración del Día Internacional de los Museos en 20186, implica la construcción de redes para la creación de nuevas audiencias. Si pensamos que una pintura del siglo XV llegaba a recorrer grandes distancias para encontrar nuevas miradas y que hoy está disponible en la velocidad y virtualidad de la pantalla digital, entendemos que el peso de esta mirada también es ligero, donde la obra de arte a menudo se encuentra con miradas ocasionales y distraídas. La producción centrada en la atención del público es uno de los desafíos del museo del nuevo milenio.

El el último año, algunas iniciativas digitales en museos fueron producidas bajo la urgencia de la pandemia COVID-19, para responder de manera rápida e inadvertida a la necesidad de aislamiento social y, por tanto, la suspensión temporal de las visitas presenciales. Pero, como ya mencionado, el hecho de poner contenidos online no garantiza el éxito o la relevancia de la experiencia virtual (Beiguelman, 2020). El trabajo de adaptar siglos de historia y cultura

\footnotetext{
${ }^{6}$ ICOM. "Hyperconected museums: new approaches, new publics". $<$ http://imd.icom.museum/pasteditions/2018-museos-hiperconectados-enfoques-nuevos-publicos-nuevos/ $>$ [Consulta: 20/02/2021]
} 
al diálogo a través de la pantalla digital, portátil y particular, no solo abre una puerta entre dos mundos, sino que provoca una reconfiguración estructural de los museos del siglo XXI.

Actualmente, las instituciones culturales que establecen múltiples conexiones con los diferentes tipos de público son las que pueden lograr un mayor impacto social y la presencia digital es fundamental para alcanzar este objetivo en un mundo cada vez más virtual, conectado y online. Así siendo, proyectos que fomentan la capacitación de los profesionales de museos para traducir las misiones de estas instituciones en el processo de transformación digital son fundamentales para que la práctica digital evolucione de forma consciente y eficaz en este ámbito.

Una parte importante de la transición de dinámicas relacionales entre público y museos debe partir del trabajo que ya se hace en las instituciones, y que sus agentes comprendan las especificidades de lo digital para que puedan adaptar con confianza la creación del contenido que organiza los saberes que salvaguardan los museos es el camino más sostenible dentro de la realidad de la transformación digital.

Finalmente, más allá del encuentro, vivimos en la época de la mergullo del espectador en la obra de arte, con el surgimiento de iniciativas culturales como L'Aterlier des Lummiéres de Paris, un centro de arte digital inaugurado en 2018 y especializado en exposiciones inmersivas, con obras de artistas reconocidos de la historia del arte proyectadas en tamaño gigante en las paredes, suelos y techos del centro cultural, que recuerdan los Dioramas de Louis Daguerre en el siglo XIX, otro momento de inflexión para la construcción de experiencias culturales.

Es importante comentar que es necesaria una distancia histórica para medir el impacto real que este tipo de experiencia puede generar en el espectador contemporáneo. Desde que el Renacimiento descubrió el pliegue y el campo oculto, cuando surgieron nuevas perspectivas para la mirada, nuestros sentidos biológicos se complementaron en éxtasis, placer y belleza. Desde las fantásticas representaciones del "Jardín de las Delicias" (El Bosco, 1504), pasando por la simetría clásica de "Santa Cena" (Leonardo Da Vinci, 1495-1498) y, más tarde, entrando en el mundo sistemático y experimental de "Dia y Noche" (MC Escher, 1938), vemos que el arte está en constante y paulatina deconstrucción de dimensiones, como preparándonos para ver muchas otras dimensiones aún no imaginadas (Cavalcanti, 2011).

Finalmente, toda la memoria depende, de antemano, del olvido. Para que exista la memoria, es necesario percibir el pasado como un tiempo diferente, como un antecedente del tiempo actual. Ahora podemos viajar al pasado a través de la ventana digital que llevamos a todas partes, que también es un mecanismo para registrar nuestro tiempo, para la producción de memoria. Culturalmente, la lectura de imágenes del pasado permite el reconocimiento de diferentes personalidades individuales, sociales y políticas. En el Renacimiento digital, la memoria del pasado permite a sujetos y sociedades construir su identidad además de proyectar una visión de futuro a través de la pantalla digital. 


\section{Referencias}

BEIGUELMAN, G. (2020) “Atropleados pela pandemia, museus rastejam na internet" en Folha de São Paulo, 17 de abril de 2020.

$<$ https://www1.folha.uol.com.br/ilustrada/2020/04/atropelados-pela-pandemia-museusrastejam-na-idade-da-pedra-da-internet.shtml> [Consulta: 13/01/2021].

BETANCOURT, M. (2010). “A Aura do Digital” en PERSSINOTTO, P. y BARRETO, R. (coord.), Teoria digital: dez anos do FILE - Festival Internacional de Linguagem Eletrônica. São Paulo: Imprensa Oficial do Estado de São Paulo: FILE, 2010, pp. 40-59.

CAVALCANTI, C. B. C. (2011). O conhecimento em exposição. Novas linguagens da comunicação como construção multidirectional de conhecimento e de percepção do mundo contemporâneo. Tesis Doctoral en Comunicación y Cultura. Rio de Janeiro: Universidade Federal do Rio de Janeiro, 2011.

ECO, U. (2014). El museo del tercer milenio en ECO, U. y PEZZINI, I. El Museo. Madrid: Casimiro Libros, p.15-41.

EDUCASE y NEW MEDIA CONSORTIUM. Horizon Report : Museum Edition, 2010$2016<$ https://library.educause.edu/resources/2016/1/horizon-report-museum-edition2010-2016\%20> [Consulta: 01/02/2021] [institucional].

GSM Association [2020]. THE MOBILE ECONOMY 2020.

$<$ https://www.gsma.com/mobileeconomy/wpcontent/uploads/2020/03/GSMA_MobileEconomy2020_Global.pdf > [Consulta: 13/02/2021] [institucional].

JIMÉNEZ-BLANCO, M. D. (2014). Una Historia del Museo en Nueve Conceptos. Madri: Ediciones Cátedra.

MALRAUX, A. (1956). "El museo imaginário” en Las voces del silencio: visión del arte. Buenos Aires: Emecé.

QUÉAU, P. (1995). Lo virtual. Virtudes y vértigos. Barcelona: Ed. Paidós Ibérica.

REGUERA, I. (2010). "Aby Warburg, inventor del museo virtual” en El País. 01 de maio de 2010. <http://elpais.com/diario/2010/05/01/babelia/1272672757_850215.html> [Consulta: 01/02/2021].

RICO, J. C., (coord.) (2009). ¿Cómo se cuelga un cuadro virtual? Las exposiciones en la era digital. Gijón: Ediciones Trea.

VILLAESPESA, E. C. (2015). Measuring Social Media Success: The value of the Balanced Scorecard as a tool for evaluation and strategic management in museums. Tesis doctoral inédita. University of Leicester, School of Museum Studies, 2015.

WARBURG, A. (2010). Atlas Mnemosyne. Madrid: Akal, D. L. 